positively related to risk and there is a negative association between HDL cholesterol and non-HDL cholesterol. Thus the real test of whether such a ratio has any independent predictive ability is to fit a logistic model relating risk of ischaemic heart disease to both nonHDL cholesterol and the HDL cholesterol to total cholesterol ratio. In our data the ratio then made no significant contribution to risk of major ischaemic heart disease.

\section{Conclusion}

Despite the extent of current opinion about the protective effect of HDL cholesterol on ischaemic heart disease, there appears to be reasonable doubt regarding the strength and validity of this association. Data from the British Regional Heart Study have not shown HDL cholesterol to be an independent risk factor for ischaemic heart disease. It is possible that $\mathrm{HDL}$ cholesterol has a greater role in other communities with lower concentrations of total cholesterol and taking different diets. ${ }^{21}$ The prospective studies reviewed in this paper are consistent in finding lower HDL cholesterol concentrations in men developing major ischaemic heart disease events. The difference, however, appears to be small and is reduced after appropriate adjustment for other risk factors. While HDL cholesterol will continue to be a focus of considerable interest and concern-particularly regarding its role in the removal of cholesterol from peripheral tissues-it does not appear to be a risk factor of importance to the present generation of middle aged British men.

The British Regional Heart Study is supported by grants from the British Heart Foundation, the Medical Research Council, and the Department of Health and Social Security. Serum total cholesterol and HDL cholesterol measurements were carried out in the Wolfson Research Laboratories, supported by the DHSS. We are extremely grateful to the Framingham study and the Israeli Heart Disease study for permission to use unpublished data (presented in figure 2).

\section{References}

1 Miller GJ, Miller NE. Plasma high density lipoprotein cholesterol and development of ischaemic heart disease. Lancet 1975; i: 16-9.

Smith E. HDL-should we be 'chasing' it now? Journal of Human Nutrition 1980;34:59-62.

3 Shaper AG, Pocock SJ, Walker M, Cohen NM, Wale CJ, Thomson AG. British Regional Heart Study: cardiovascular risk factors in middle-aged men in 24 towns. Br Med f 1981;283:179-86.

4 Shaper AG, Pocock SJ, Walker M, Phillips AN, Whitehead TP, Macfarlane PW. Risk factors fo ischaemic heart disease: the prospective phase of the British Regional Heart Study. $\mathcal{F}$ Epidemiol Community Health 1985;39:197-209.

5 Walker $M$, Shaper AG. Follow-up of subjects in prospective studies based in general practice. $f R$ Coll Gen Pract 1984;34:365-70.

6 Thelle DS, Shaper AG, Whitehead TP, Bullock DG, Ashby D, Patel I. Blood lipids in middleaged British men. Br Heart f 1983;49:205-13.

7 Whitehead TP, Bullock DG, Carter TJN, et al. High density lipoprotein cholesterol analysis. News Sheet of the Association of Clinical Biochemists 1979;190:7-8.

8 Goldbourt U, Medalie JH. High density lipoprotein cholesterol and incidence of coronary hear disease-the Israeli Ischaemic Heart Disease Study. Am f Epidemiol 1979;109:296-308.

9 Shaper AG, Cook DG, Walker M, Macfarlane PW. Prevalence of ischaemic heart disease in middle-aged British men. Br Heart f 1984;51:595-605.
macer

10 Shaper AG, Cook DG, Walker M, Macfarlane PW. Recall of diagnosis by men with ischaemic heart disease. Br Heart $\mathcal{F}$ 1984;51:606-11

11 Keys A, Karvonen MJ, Punsar S, Menotti A, Fidanza F, Farchi G. HDL serum cholesterol and 24-year mortality of men in Finland. Int f Epidemiol 1984;13:428-35.

12 Keys A. Alpha lipoprotein (HDL) cholesterol in the serum and risk of coronary heart disease and death. Lancet 1980;ii:603-6.

13 Gordon T, Castelli WP, Hiortland MC, Kannel WB, Dawber TR. High density lipoprotein as a protective factor against coronary heart disease. The Framingham study. Am $\mathcal{J}$ Med 1977;62:707-14.

14 Enger SC, Hjermann I, Foss OP, et al. High density lipoprotein cholesterol and myocardial infarction or sudden death: a prospective case-control study in middle aged men of the Oslo study. Artery 1979;5:170-81.

15 Miller NE, Thelle DS, Førde OH, Mjøs OD. The Troms $ø$ Heart Study. High-density lipoprotein and coronary heart disease: a prospective case-control study. Lancet 1977; i:965-8

16 Medalie JH, Kahn MA, Neufeld HN, Riss E, Goldbourt U. Five year myocardial infarction incidence-II: association of single variables to age and birthplace. $\mathcal{F}$ Chronic Dis 1973;26:32949.

17 Yaari S, Goldbourt U, Even-Zahar S, Neufeld H. Associations of serum high density lipoprotein and total cholesterol with total, cardiovascular and cancer mortality in a 7-year prospective study of 10,000 men. Lancet 1981;i:1011-5.

18 Goldbourt U, Holtzman E, Neufeld HN. Total and high density lipoprotein cholesterol in the serum and risk of mortality: evidence of a threshold effect. $\mathrm{Br}$ Med $\mathcal{X}$ 1985;290:1239-43.

19 Neaton JD, Kuller LH, Wentworth D, Borhani NO. Total and cardiovascular mortality in relation to cigarette smoking, serum cholesterol concentration, and diastolic blood pressure relation to cigarette smoking, serum cholesterol concentration, and diastolic blood pres

20 Shaper AG, Pocock SJ, Phillips AN. Alcohol and ischaemic heart disease in British men [Abstract]. Eur Heart f 1985;6 (suppl 1):56.

21 Miller GJ, Miller NE. Dietary fat, HDL cholesterol and coronary disease: one interpretation. Lancet 1982;ii: 1270-1.

\title{
Children intoxicated by alcohol in Nottingham and Glasgow, 1973-84
}

\author{
JOHN O BEATTIE， DAVID HULL， FORRESTER COCKBURN
}

\begin{abstract}
The circumstances of ingestion, clinical course, and long term sequelae were examined retrospectively in 143 children (108 boys, 35 girls) admitted with acute alcohol intoxication in Glasgow and Nottingham over the 12 years 1973-84. Fifty three of the children were aged less than 7 years and 90 were aged 7-14. Twelve of the children were hypoglycaemic on arrival at hospital. Trauma related to intoxication occurred in 14 cases, and nine boys became drunk under duress, which in four cases was associated with sexual abuse.
\end{abstract}

\footnotetext{
Department of Child Health, Queen's Medical Centre, Nottingham NG7 2UH

JOHN O BEATTIE, MRCP, DCH, senior paediatric registrar

DAVID HULL, FRCP, DCH, professor of child health
}

Department of Child Health, Royal Hospital for Sick Children, Glasgow G3 8SJ

FORRESTER COCKBURN, MD, FRCP, professor of child health

Correspondence to: Dr J O Beattie, Stirling Royal Infirmary, Stirling FK8 2AU.

\section{Introduction}

Each year roughly 1000 children aged under 15 are admitted to hospital in England and Wales suffering from acute alcohol intoxication (Department of Health and Social Security, personal communication). Despite the relative frequency of such cases there have been few reports on the problem, ${ }^{1}$ most studies having highlighted occasional dramatic complications. ${ }^{2}$ The aim of our study was to assess the origins and overall medical importance of such incidents by systematically examining the circumstances of ingestion, the clinical course, and long term sequelae in all children with alcohol intoxication admitted to two paediatric centres in Britain, the Royal Hospital for Sick Children, Glasgow, and the children's department of University Hospital, Nottingham.

\section{Patients and methods}

The children's department at University Hospital, Nottingham, provides a primary paediatric referral service for 184000 children aged under 15 in the city of Nottingham and the surrounding rural areas. In Glasgow the Royal Hospital of Sick Children provides a similar acute service for about 200000 children. Teenagers in Nottingham who require acute medical care may be 
admitted to the adult medical wards at University Hospital; in Glasgow such admissions are distributed among five acute adult medical units. The case records of all children aged under 15 admitted to the two hospitals from January 1973 to December 1984 with a primary diagnosis of acute alcohol intoxication (poisoning) were examined retrospectively; these included records of young teenagers admitted to the adult wards in Nottingham. Children who had ingested alcohol in a form other than a beverage were excluded. Demographic, clinical, and laboratory details were extracted.

\section{Results and comments}

During the 12 years 143 children were admitted with acute alcohol intoxication. Table I shows the age and sex distributions of these children. time of ingestion was known. Of the 53 children aged under 7, 51 obtained alcohol within the parental home and 50 drank it there. Generally the children drank on their own, only 10 drinking with a sibling or friend. Most episodes seemed to be related to accidental access to alcohol in the home; this was often aggravated by domestic upset or an apparent general lack of surveillance. At least 12 of the young children came from single parent families. Fifteen cases were examples of the "classic scenario" of ingestion of alcohol by toddlers, ${ }^{3}$ the incident occurring in the early morning while the parents were asleep, often with bottles left available after social events the previous night. Four toddlers became intoxicated while actually attending family celebrations, and two children were given alcohol inappropriately by a parent or babysitter. Five of the young children who attended hospital were accompanied by drunken parents.

By contrast, the episodes of intoxication in the 7-14 year olds mainly

TABLE I-Number of children intoxicated by alcohol in Nottingham and Glasgow 1973-84 by age and sex

\begin{tabular}{|c|c|c|c|c|c|c|c|c|c|c|c|c|c|c|}
\hline Age (years): & 1 & 2 & 3 & 4 & 5 & 6 & 7 & 8 & 9 & 10 & 11 & 12 & 13 & 14 \\
\hline Boys $(n=108)$ & 2 & 6 & 16 & 8 & 3 & 1 & 6 & 7 & 6 & 13 & 16 & 17 & 4 & 3 \\
\hline
\end{tabular}

TABLE II-Age (expressed as a decimal), time of ingestion of alcohol (to within \pm 30 minutes), and plasma glucose concentrations on admission in 12 children with clinical hypoglycaemia

\begin{tabular}{cccc}
\hline Case No & $\begin{array}{c}\text { Age } \\
\text { (years) }\end{array}$ & Time & $\begin{array}{c}\text { Plasma glucose } \\
(\mathbf{m m o l} /)\end{array}$ \\
\hline 1 & 3.57 & 1200 & $1 \cdot 8$ \\
2 & 3.52 & 1100 & 1.0 \\
3 & 4.84 & 0800 & 1.6 \\
4 & 2.06 & 2330 & 0.9 \\
5 & 3.72 & 1400 & 0.5 \\
6 & 2.44 & 1100 & 0.7 \\
7 & 3.29 & 0900 & 1.0 \\
8 & 8.89 & 2200 & 0.9 \\
9 & 10.81 & 1000 & $2 \cdot 0$ \\
10 & 4.32 & 1000 & $2 \cdot 1$ \\
11 & 3.96 & 1030 & 2.2 \\
12 & 5.20 & 0950 & 2.6 \\
\hline
\end{tabular}

Conversion: SI to traditional units-Glucose: $1 \mathrm{mmol} / \mathrm{l} \approx 18$ $\mathrm{mg} / 100 \mathrm{ml}$. occurred during the evening, 62 of the 87 children for whom the time of ingestion was known drinking between $5 \mathrm{pm}$ and midnight. In this group only 29 obtained alcohol in the parental home, 34 obtaining it in a friend's home. Twenty five procured it from commercial licensed premises. The source of alcohol was unknown in two cases

Only 26 of the 7-14 year olds drank within the parental home, 36 becoming intoxicated in a friend's home or at an organised social event. Twenty eight of these children drank out of doors, mainly in parks and fields. Group drinking was common in this older group, 45 drinking with others. Sherry was the favourite drink among the young children, while more spirits, beer, and wine were taken by the older group.

Most of the incidents of intoxication in the older children seemed to be acts of simple experimental bravado in the absence of parental supervision. Ten children, however, had a history of chronic behaviour problems, one depressed child being admitted drunk twice in the same year (details of only the first admission are included here). No child seemed to have a background of regular alcohol use or abuse, although two of those with behaviour disturbances were known to have indulged in solvent abuse in the past. One child took diazepam and alcohol as an attention seeking exercise.

Nine of the older children, all boys, became intoxicated after drinking

TABLE III-Number of children admitted with alcohol intoxication each year in Nottingham and Glasgow, 1973-84

\begin{tabular}{|c|c|c|c|c|c|c|c|c|c|c|c|c|}
\hline & 1973 & -74 & -75 & -76 & -77 & -78 & -79 & -80 & -81 & -82 & -83 & -84 \\
\hline \multicolumn{13}{|c|}{ Nottingham } \\
\hline$<7$ years & & 14 & 1 & & 4 & 6 & 1 & 2 & 2 & 2 & & 5 \\
\hline$\geqslant 7$ years & 1 & 7 & 2 & 6 & 1 & 10 & 7 & 7 & 7 & 9 & 4 & 14 \\
\hline \multicolumn{13}{|c|}{ Glasgow } \\
\hline$<7$ years & & 2 & 1 & 3 & 1 & 2 & 2 & & & & 2 & 1 \\
\hline$\geqslant 7$ years & 1 & 2 & 1 & 2 & 2 & 1 & 2 & & 2 & 1 & 1 & 2 \\
\hline
\end{tabular}

Two distinct populations were admitted-namely, 53 children aged less than 7 , among whom the peak number of admissions occurred at the age of 3 , and 90 children aged 7-14, among whom the peak number of admissions occurred at the age of 12 . Altogether 108 boys and 35 girls were admitted, giving an overall male to female ratio of $3: 1$. The preponderance of boys was especially pronounced in the older group.

Seasonal variation in the rate of admission was evident, especially among the older children. The peak admission rates occurred in April, August, and December and January, coinciding with school holidays and perhaps also with an increased availability of alcohol, especially over the Christmas period. Thirty five children were admitted in December and January.

\section{CIRCUMSTANCES OF INGESTION}

The young children generally drank alcohol during the day and at home, intoxication occurring between 8 am and $6 \mathrm{pm}$ in 39 of the 50 cases in which under duress. In five of these incidents, in one of which the boy was threatened with an air rifle, the motive appeared to be simple malice on the part of older, aggressive adolescent boys, but in the four remaining cases attempted or actual sexual abuse by adult men was the apparent reason. One 13 year old boy was forced to drink at knife point before being sexually assaulted.

\section{MEDICAL CONSEQUENCES OF INTOXICATION}

All of the children had important clinical signs of alcohol intoxication on admission, for it is not the policy of either hospital to admit mild or asymptomatic cases. Seventy five children had a blood alcohol concentration above $21.7 \mathrm{mmol} / 1(100 \mathrm{mg} / 100 \mathrm{ml})$ on admission; in 17 it was greater than $43.4 \mathrm{mmol} / 1(200 \mathrm{mg} / 100 \mathrm{ml})$. These 17 children were deeply unconscious, responding only to painful stimuli, and all required intensive care. The highest blood alcohol concentration $(85 \cdot 3 \mathrm{mmol} / 1(393 \mathrm{mg} / 100 \mathrm{ml}))$ occurred 
in a 10 year old girl, who was also the most seriously ill of all those admitted. She became unconscious after drinking at home, inhaled vomit, and required resuscitation on arrival at hospital. She developed cerebral oedema and decerebrate posturing after her anoxic episode and required intensive treatment for four days. She appeared not to have sustained any neurological damage.

Twelve children arrived at hospital deeply unconscious from hypoglycaemia, predominantly after drinking in the morning (table II); one young child was fitting. All responded clinically to intravenous dextrose Ten of these 12 children were aged under 7 , giving an incidence of $19 \%$ for this complication in the younger children.

Hypothermia (core temperature less than $35^{\circ} \mathrm{C}$ ) occurred in nine children and was apparently related to drinking outdoors.

Secondary physical complications of intoxication were also seen. Ten children sustained head injuries with unconsciousness after drunken falls, four requiring suturing of facial lacerations. Two other children had a haematemesis, and one required treatment for burns. Despite these problems none of the children in the study appeared to develop any long term physical problems.

Table III shows the number of children admitted to the two hospitals in each year of the study. In Nottingham unexplained peak admission rates occurred in the younger children in 1974 and in the older children in 1984. Overall, over three times as many children were admitted in Nottingham $(112 ; 37$ aged under 7$)$ compared with Glasgow ( $31 ; 14$ aged under 7).

\section{Discussion}

Alcohol intoxication should be considered in any child with unexplained alteration in consciousness. ${ }^{4}$ In young children it is usually due to their formidable ability to explore their environment and sample its delights. Such incidents are especially likely if surveillance in the home is compromised by domestic stresses or if parents themselves are drinking. In addition, many parents seem ill informed of the potential toxicity of alcohol in young children so that access to alcoholic drinks within the home may be relatively easy for the child.

As our study shows, serious complications may occur. This is partly related to the pharmacology of alcohol in children. Youngsters rapidly drink large amounts in relation to their body weight and quickly produce high blood alcohol concentrations. A toddler's ability to metabolise this alcohol load is limited, for hepatic alcohol dehydrogenase activity is not mature until the age of $5 . .^{5}$ The potential for severe neurological depression is therefore high. Life threatening alcohol poisoning is especially likely in this age group. Intravenous naloxone may be tried in deeply unconscious children, ${ }^{6}$ and peritoneal dialysis may be required. ${ }^{7}$ Skilled respiratory support must be available.

Although the association of alcohol ingestion and hypoglycaemia in young children is well known, our study suggests that it occurs more commonly than was previously appreciated. ${ }^{8}$ The hypoglycaemia primarily results from inhibition of hepatic gluconeogenesis. ${ }^{9}$ Obligate overnight fasting in children may potentiate this effect by reducing hepatic glycogen stores, so that toddlers who drink alcohol in the early morning are particularly vulnerable to this complication. Clinical recognition of the hypoglycaemia may be difficult, but delay in treatment may lead to death or permanent neurological damage. ${ }^{10}$ Intravenous dextrose solution is the treatment of choice, for oral treatment is dangerous and not dependable and glucagon is ineffective if hepatic glycogen stores are depleted.

Older children who become seriously intoxicated only occasionally develop hypoglycaemia, but they still face the risks of neurological depression. In addition, as most episodes of intoxication in older children occur away from parental surveillance and often outdoors traumatic or other complications are less likely to be detected early. In those cases associated with head injury it may be difficult to identify the dominant cause of the alteration in consciousness, and neurological observation should be especially vigilant.

It is important to obtain a detailed history of the circumstances of alcohol ingestion in these young people. This should include an assessment of the wider family and social circumstances. It is clearly important to identify those children with underlying psychological problems and the few who are already regularly abusing alcohol so that appropriate intervention can take place. ${ }^{11}$ Children with behaviour disorders have an increased risk of becoming problem drinkers in later life. ${ }^{12}$ Possible sexual abuse should also be considered, ${ }^{13}$ especially if the incident included an element of duress or if adults played a part.

Even isolated incidents in children without underlying emotional problems may be more important than they appear superficially. Drinking alcohol is an integral part of our way of life, and most children learn about its use from an early age.$^{14}$ If parental attitudes to alcohol deny their children knowledge of its effects, however, such innocence may be counterproductive when the children finally encounter alcohol in later life. In addition, a fundamentalist antialcohol approach by parents may heighten the attractiveness of alcohol to adolescents seeking a rebellious expression of their independence. ${ }^{15}$ There is some evidence that children who are introduced to alcohol outside the home by their peers and who drink surreptitiously and beyond parental control may go on to be heavier drinkers as young adults. ${ }^{16}$ In such cases the family's attitudes to alcohol should be explored and appropriate advice given.

A report from Newcastle highlighted an increasing problem with intoxication among adolescent boys in that city. ${ }^{17}$ Our study does not suggest a similar trend in Glasgow or Nottingham, and national yearly admission rates also seem to be fairly stable (Department of Health and Social Security, personal communication). Nevertheless, the pronounced difference in the apparent size of the problem in our two cities, where hospital admission policies are identical, is intriguing. Comparison of admission of older drunken children was not possible because such children admitted to adult wards in Glasgow were not included, but the difference in the numbers of the under $7 \mathrm{~s}$ admitted in the two cities was striking. Might it be that parents (and primary care doctors) in Glasgow, where drunkenness among adults is a relatively common sight, ${ }^{18}$ are more confident and experienced in dealing with alcohol intoxication at home?

We are indebted to the consultant paediatricians and physicians in Glasgow and Nottingham for allowing us access to information on children under their care. We also thank Sister E Kobryn and Nurse A H Rogers, paediatric accident and emergency department, University Hospital, Nottingham, and Ms G Sinclair, department of child health, Glasgow, for help with this study, and Mrs Wendy Thraves, who typed the manuscript.

\section{References}

1 Le Conte M, Saint-Jacques, I, Cagnet R, Vellieux F, Boissiere H. Le coma alcoolique par intoxication accidentelle chez l'enfant. Sem Hop Paris 1978;54:315-24.

2 Heggarty HJ. Acute alcoholic hypoglycaemia in two 4 year olds. Br Med f 1970;113:280.

2 Heggarty HJ. Acute alcoholic hypoglycaemia in two 4 year olds. Br Med f 1970;113:280.
3 Bradford DE. Alcohol related hypoglycaemia in children again-a Sunday morning hazard? Bradford DE. Alcohol related hypoglycaemia in childre
British foumal on Alcohol and Alcoholism 1979;14:84-5.

4 Malcolm JB, Benjamin B, Sorbie AL, Auchterlonie IA. Alcohol intoxication, an underdiagnosed problem? Arch Dis Child 1985;60:762-3.

5 Hollstedt C, Olsson O, Rydberg U. The effect of alcohol on the developing organism. Med Biol 1977;55:1-14.

6 MacKenzie AI. Naloxone in alcohol intoxication. Lancet 1979;i:733-4.

7 Dickerman JD, Bishop W, Marks JF. Acute ethanol intoxication in a child. Pediatrics 1968;42:837-40.

8 Cornblath M, Schwartz R. Disorders of carbohydrate metabolism in infancy. Philadelphia: WB Saunders, 1966:224-6. (Major Problems in Clinical Pediatrics vol 3.)

9 Wright J. Alcohol-induced hypoglycaemia. British fournal on Alcohol and Alcoholism 1979;14:

174-6.
10 Cummins LH. Hypoglycemia and convulsions in children following alcohol ingestion. $\mathcal{F}$ Pediatr 1961;58:23-6.

11 Ritson B. Treatment and evolution of alcohol-dependent children and adolescents. In: Jeanneret $\mathrm{O}$, ed. Child health and development. Vol 2. Alcohol and youth. Basle: Karger, 1983:108-18.

12 Robins LH, Bates WM, O'Neal P. Adult drinking patterns in former problem children. In: Pittman DJ, Snyder CR, eds. Society, culture and drinking patterns. New York: Wiley, 1962: 395-412.

13 Anderson LS. Notes on linkage between the sexually abused child and the suicidal adolescent. $f$ Adolesc 1981;4:157-62.

14 Jahoda G, Crammond J. Children and alcohol. London: HMSO, 1972.

15 Davies JB. Children's and adolescents' attitudes towards alcohol and alcohol-dependence. In Jeanneret O, ed. Child health and development. Vol 2. Alcohol and youth. Basle: Karger, 1983:
42-53.

16 Davies JB, Stacey B. Teenagers and alcohol: a developmental study in Glasgow. London: HMSO, 1972.

17 Lawson GR, Craft AW, Jackson RH. Changing pattern of poisoning in children in Newcastle 1974-81. Br Med f 1983;287:15-7.

18 Departmental Committee on Scottish Licensing Law. Report. London: HMSO, 1972. (Clayson report.)

(Accepted 10 December 1985) 